\title{
Issues of Practical Teaching in Vocational-Technical Schools in China and Their Countermeasures
}

\author{
Wei Zhang \\ Faculty of Education, Qufu Normal University \\ Qufu 273165, Shandong, China \\ E-mail: zhangwei5633@126.com
}

\begin{abstract}
There exist a good many issues in practical teaching in vocational-technical schools in China, such as underemphasis on the part of all parties involved in practical teaching, dated practical teaching content, irrational curriculum provision in practical teaching, shortage of "double-quality" teachers and space for improvement of teaching assessment, etc.
\end{abstract}

Keywords: Vocational-technical education, Practical teaching, Double-quality teachers, Teaching assessment

The primary task of vocational-technical schools is to cultivate for the society applied-based talents with strong practically operational capacity, competence to resolve practical problems and to deal with emergencies. Currently, although educational philosophy of vocational-technical schools has been changed, still the strength of practical teaching is far from enough, and training of students with cumulative knowledge is still in the process. Quite a large majority of graduates cannot independently finish what is assigned to them within quite a long period of time after being engaged in a position. Tracing to its cause, it is that their practical learning at school is ignored, and they don't have many opportunities to get into contact with practical problems, so once they step into a post of work, they cannot make themselves immediately adapted to their roles. In order to better adapt to the rapidly development economic demands at present, vocational-technical schools should promptly resolve existing practical teaching issues.

\section{Primary issues in practical teaching in vocational-technical schools}

Persistent prosperity of Chinese economy has brought opportunities for development of vocational-technical schools, but also challenges to high demand on quality of working staff. Since students at school mainly learn basic theoretical knowledge in books, but there is rarely any chance for them to learn practical operational skills, with fewer practice opportunities and imperfect practice competence, the situation is caused in which quantity \& quality, and teaching \& employment are difficult to get integrated. Specifically speaking, issues existing in practical teaching in vocational-technical schools are mainly reflected in the following several aspects.

\subsection{Under-estimation on practical teaching}

Vocational-technical schools are targeted at cultivating practical application skills of students, with both property of higher education and property of vocational technique. The fundamental characteristics of vocational-technical schools should be not to pursue systematicness and completeness of theory, but to emphasize integrity and practicability of practical capacity. Students from vocational-technical schools should place extra emphasis on basic competence and skills required for practice in technical fields in their majors, with the precondition that they grasp requisite basic theoretical knowledge and professional knowledge.

However, due to influences of traditional education for quite a long time, vocational-technical schools still follow the traditional educational mode, and experiments and practice courses in most schools perform practically no function at all. For example, experiments and practical courses are not qualitatively distinguished from courses of knowledge impartation, teachers just echo what the books say, students copy notes, and experiments and practical courses become courses of "an armchair strategist". In terms of teaching content, theory is overemphasized, while practical training is ignored; theoretical teaching is dominant, while practical teaching is placed at a secondary position, which cannot reflect characteristics of vocation and technique. Furthermore, vocational-technical schools even become general compression-type regular higher education. In such way, it is an established fact that students are lacking in practical skills and practical manipulative ability, which cannot satisfy demand of the society on vocational-technical talents, and which may make vocational-technical education deviate from normal educational philosophy. For the time being, some vocational-technical schools merely regard practical teaching as a means to train skills of students, but ignore its comprehensive functions in training of their knowledge, capacity and quality. Therefore, functions and effects of practical teaching cannot be brought into full play. 


\subsection{Irrational curriculum project of practical teaching}

Curriculum project of vocational-technical schools is affected by the traditional education in that there are too many and relatively difficult theoretical courses, and most courses refer to materials of regular institutions of higher education, while there are few vocational and technical courses, and most of these courses are relatively easy and dated. Courses with high speciality and practicalness are rarely taught in curriculum schedules of these schools, especially application of new process, new technology, and new professional instructional software, etc. Practical teaching go out of joint with theoretical teaching, because practical teaching cannot comprehensively apply knowledge learned in theoretical courses and lag behind rapid development of high and new technology. Although vocational-technical schools focus on participation of enterprises in terms of formulation of practical teaching program and selection of teaching content, it is still difficult for them to realize that due to multitudinous reasons. Even if that is realized, it is usually the case that they adopt a transformed type of their own resources, but not that they allow students to go into actual work. How can students trained in such way correspond with standards of talents required by the society?

\subsection{Weakness of teacher force in practical teaching}

Teachers are the most important resource in vocational-technical schools, and their practical capacity plays a crucial role in training of application-based talents. However, a large majority of teachers in vocational-technical schools come from other disciplines, with few practice experiences. Therefore, a large number of teachers don't have working experiences in enterprises. Besides, they are lacking in necessary practice afterwards, so it is difficult for them to conduct "application-based" education on students. Furthermore, establishment of teaching materials lags behind, and content of some materials is alienated from reality, so it's hard for them to achieve a perfect education goal. More specifically, there exist the following issues.

Firstly, lack of "double-quality" teachers. Currently, young teachers in most vocational-technical schools account for a larger proportion, most of whom "enter schools from schools" and are short of specific working experiences in the forefront of enterprises, so their manipulative ability is generally far from enough. It is inevitable that a teaching force constituted by these teachers is relatively weak in terms of practical teaching, and their theoretical teaching usually goes out of joint with practice. Secondly, the number of part-time teachers occupies a small proportion in practical teaching. In recent years, in order to promote close connection between colleges and universities and economic and industrial circles and to maintain flexibility of teachers, and also in order to increase efficiency in school management, colleges and universities in developed countries invite a large proportion of part-time teachers. Invitation of a large number of part-time teachers is a trend for vocational-technical schools to share human resources with other institutions, which can save considerable expenditure. In addition, in order to keep synchronized development of technology with forefront of the production, no other method is better than inviting teachers from technicians in the forefront of the production, because information and methods they introduce and their experiences in occupation are not at command of teachers in vocational-technical schools. For the time being, due to issues, such as limited teaching funds and weak teaching force etc, in vocational-technical schools, practice teaching staff are not paid due attention, which results in such a situation that teachers are not willing to give correct guidance on practice teaching. Teachers are the leading factor in teaching, and, without doubt, without perfect teachers in a school and without stability of teaching staff, the quality of practice teaching is unlikely to get deserved guarantee.

\subsection{Light weight of practical teaching in the system of teaching assessment}

At present, practical teaching assessment in vocational-technical schools is mainly based on $<<$ Standard Evaluation Target System of Training Qualified Personnel of Higher Vocational Colleges and Academies $>>$. However, among the 15 secondary indexes, what is directly interrelated with practical teaching are merely "conditions of practical teaching" under the primary index of "teaching conditions and their application" and "training of occupational competence" under the primary index of "teaching establishment and reform", and their weight coefficient only accounts for $13 \%$ of the total. Weight of practical teaching is unbalanced, which is disproportional compared with its position in vocational-technical education.

\section{Thoughts on countermeasures of practical teaching issues in vocational-technical schools}

Existing issues in vocational-technical schools are generated in their own development, but it is not unchangeable. Given current issues in practical teaching, it is necessary to make attempt in the following several aspects.

\subsection{To deepen cognition and to transform concepts}

Resolution of issues in practical teaching in vocational-technical schools rests with cognition deepening of this system and concept transforming of education. Firstly, all faculty and staff in vocational-technical education, without exception, should have a systematic, comprehensive and in-depth cognition in educational philosophy of vocational-technical schools. Only updating and switching traditional educational concept and determining direction can ensure successful progress of strengthening practical teaching in vocational-technical schools. Switching the concept includes three aspects: firstly, to organize middle management staff to deeply learn and study theory of vocational and technical 
education; secondly, to concentrate training on the extensive teachers; thirdly, to educate on students by all sorts of means. Through propaganda and learning of public opinions on a large scale, a perfect atmosphere emphasizing practical teaching should be built within the schools, and educational philosophy and thinking of educators should be changed. Each one should pay sufficient attention to practical teaching with consciousness whether in thinking or in action, so as to take the initiative in organizing and implementing each teaching assignment in accordance with goals of school running.

\subsection{To offer courses based on goal of school running and to update timely teaching content}

The primary task of vocational-technical schools is to cultivate application-based talents proficient in both theory and competence. In order to achieve the goal, they have to increase proportion of practical teaching. Based on the principle of "competence as the standard", we should attempt to explore a new curriculum system. Optimization and integration is necessary for professional courses, together with pertinence and practicalness. The proportion of practical teaching should be increased on a large scale in the entire teaching program, so as to achieve a rational proportion between hours of theoretical teaching and hours of practical teaching. In the content of practical teaching, traditional demonstration and replication experiments should be reduced, while designable, comprehensive and applicable experiments should be largely increased, so as to form fundamental comprehensive practice ability, competence of professional technology application and operational skills. Such practical training should be particularly paid attention to as new manufacturing technique and new technology, etc. Selection and compilation of teaching materials should concentrate on internship teaching, and should detach internship materials from theoretical materials which they are originally attached to. Experimental (internship, practical training) guidebooks, quality standard of practical teaching and assessment criteria of practical teaching etc, should be researched according to the teaching program in order to formulate scientific and normative practical teaching materials. In compilation of practical teaching materials, introduction of "new" concepts should be paid attention to, modernized information and technology should be made full use of, corresponding and relevant courseware should be set up and advanced teaching application software should be applied for practical teaching.

\subsection{To strengthen establishment of teaching staff}

The effect of practical teaching in vocational-technical schools mainly depends on establishment of a perfect teaching team. First of all, teachers should be sent to relevant production units for short-term and medium-term practice. Those lacking in practical experiences and skills should be regularly sent to corresponding production department for specialized practice and skill practice, so as to improve their competence of practical teaching. Then, scientific service and development should be vigorously advocated. Scientific service and development is a significant component of vocational and technical education, which has a multi-directional and radiative effect upon vocational-technical schools, and encourage teachers to shift towards "double-quality". All these activities have not only strengthened connection and cooperation with production and scientific research department, but also have brought opportunities and conditions for teachers in terms of productive practice and space for improvement, reinforcing their understanding in demands of the market and accelerating renewal of teaching content and reform of teaching. Furthermore, teachers should be encouraged for further education. Professional backbone teachers are encouraged to take the exam of on-job postgraduates and to participate in training of social skills, which will be taken into consideration in annual assessment as part of th teaching load. As for teachers who are conferred with certificates of master's degree and doctor's degree as well as certificates of all sorts of skills, their post allowance should be raised. In addition, vocational-technical schools should make full use of all resources to make much acquaintance with more authoritative persons with professional knowledge and high social popularity. For instance, the schools can invite these authoritative persons as guest professors, and invite them to give more lectures to teachers and students. In such way, their industrial experiences and advantages can be brought to fully enrich our teaching. Meanwhile, we can maintain a long-term and harmonious cooperative relationship with them, and enable them to play a positive role in the establishment of teaching staff in practical teaching.

\subsection{To intensify evaluation and assessment of practical teaching}

Assessment of practical teaching and assessment of theory not only have closely linked features, but have their own characteristics. Assessment of practical teaching in vocational-technical schools should, on one hand, involve part of theoretical knowledge, and, on the other hand, should pay more attention to quantitative assessment and qualitative assessment in technology of core speciality and in vocational skills. The latter emphasizes that industrial standard and international standard should be introduced into the teaching content, and that occupation skill appraisal should be brought into the teaching program and listed in assessment and evaluation. Therefore, emphasis of assessment on practical teaching in vocational-technical schools should be placed on assessment of technology of core speciality and vocational skills and on acquisition of job qualification certificates. Assessment and evaluation of practical teaching should not only concentrate on practical competence, but should also avoid muddling through the work.

Assessment and evaluation of practical teaching should involve establishing a new evaluation and assessment system, 
which should be centered with improving students' occupational competence. Evaluation of practical teaching can be further classified into three aspects: firstly, evaluation on laboratory course, namely, to train and examine students' competence to grasp theoretical knowledge and basic skills through teaching of laboratory course; secondly, evaluation on intramural practical training, namely, to allow students to assume professional labor, field work and part of scientific and research task and to cultivate their comprehensive application competence at intramural training bases; thirdly, evaluation on extramural practical training, namely, to make comprehensive practices on a large scale at extramural training bases, and to cultivate students' work competence on the post through actual contact.

\section{References}

Wang, Jinchao. (2009). Problems and Countermeasures of Practice Teaching in Tourism Management Major. Journal of Changchun Normal University, (2).

Wei, Guiying. (2002). Reflections on Practical Teaching. Journal of Qiongzhou University, (6).

$\mathrm{Xu}$, Suqin. (2009). Problems and Countermeasures of Practice Education in High Vocational Schools. Economy of Shangdong Textile, (3).

Yu, Zhongwen, et al. (2004). On Higher Vocational Education Teaching Practice. Tsinghua University Press.

Zhang, Zhe. (2009). Problems and Countermeasures of Practice Teaching in Electronic Technology Major. Journal of Liaoning Educational Administration Institute, (2). 